EESTI NSV TEADUSTE AKADEEMIA TOIMETISED. 32. KOIDE KEEMIA. 1983 , NR. 3

ИЗВЕСТИЯ АКАДЕМИИ НАУК ЭСТОНСКОИ ССР. ТОМ 32 ХИмия. 1983, № 3

Людмила ВИНСИМАА, М. ВЕНДЕРМА, Этелка ГРАФ-ХАРЗАНН, Я. БЕРСН

\title{
РЕДКОЗЕМЕЛЬНЫЕ ЭЛЕМЕНТЫ В ФОСФАТНЫХ КОНЦЕНТРАТАХ ПРИБАЛТИКИ
}

Ludmilla VIISIMAA, M. VEIDERMA, Etelka GRAF-HARSANYI, J. BERCZI. HARULDASED MULD. METALLID BALTIKUMI FOSFAADIKONTSENTRAATIDES

Ludmilla VIISIMAA, M. VEIDERMA, Etelka GRAF-HARSANYI, J. BERCZI. RARE EARTH ELEMENTS IN THE BALTIC PHOSPHATE CONCENTRATES

Необходимость комплексной оценки и определения микроэлементного состава фосфатного сырья обусловлена масштабами его переработки и растущим значением сопутствующих элементов. В первую очередь это касается редкоземельных элементов (РЗЭ), содержание которых в фосфатах, как правило, значительно превышает кларковое $\left[{ }^{1-3}\right]$. Важно при этом определение и выделение индивидуальных Р3Э, поскольку при совместном использовании теряются их специфические свойства [ $\left.{ }^{4}\right]$.

В работах по изучению состава природных фосфатов отмечается существенное варьирование содержания Р3Э в фосфатах не только разных формаций, но и в пределах одного месторождения [ $\left.{ }^{2}\right]$. Указывается на присутствие значительных (до $50 \%$ от суммы Р3Э) количеств иттрия и лантаноидов цериевой подгруппы с возможным сдвигом максимума для некоторых фосфоритов в сторону неодима [5]. Распределение отдельных лантаноидов изучено лишь в фосфатных рудах, хотя известно, что при флотационном обогащении природных фосфатов наряду с повышением концентрации $\mathrm{P}_{2} \mathrm{O}_{5}$ увеличивается и суммарное содержание Р3Э $\left.{ }^{6}\right]$.

В настоящей работе определены содержание и состав Р3Э в фосфоритных концентратах новых перспективных месторождений Эстонской ССР (Тоолсе, Рягавере), рациональное использование которых особенно актуально. Для сравнения изучены образцы маардуского и кингисеппского фосфоритных, а также кольского и ковдорского апатитовых концентратов.

Химический состав образцов (табл. 1) показывает, что суммарное содержание оксидов РЗЭ $\left(\Sigma \mathrm{Ln}_{2} \mathrm{O}_{3}\right)$, определенное экспресс-фотоколориметрическим методом [7], в тоолсеском и рягавереском фосфоритных концентратах несколько выше, чем в маардуском и кингисеппском. Как видно из табл. 1, отношение суммы оксидов Р3Э к $\mathrm{P}_{2} \mathrm{O}_{5}$ для фосфоритов Прибалтийского бассейна составляет $0,69-1,18 \%$, что значительно выше, чем для фосфоритов большинства других месторождений как отечественных [ $\left.{ }^{8}\right]$, так и зарубежных [9]. Для апатитовых концентратов, более богатых Р3Э, эта величина достигает $1,21-2,29 \%$.

Содержание отдельных лантаноидов в фосфатных концентратах 
Химический состав образцов

\begin{tabular}{|c|c|c|c|c|c|c|}
\hline \multirow[b]{2}{*}{$\begin{array}{c}\text { Содержание, } \\
\%\end{array}$} & \multicolumn{4}{|c|}{ Фосфориты } & \multicolumn{2}{|c|}{ Апатиты } \\
\hline & $\begin{array}{l}\text { тоолсе- } \\
\text { ский }\end{array}$ & $\begin{array}{l}\text { рягаве- } \\
\text { реский }\end{array}$ & $\begin{array}{c}\text { маарду- } \\
\text { ский }\end{array}$ & $\begin{array}{c}\text { кинги- } \\
\text { сеппский }\end{array}$ & кольский & $\begin{array}{l}\text { ковдор- } \\
\text { ский }\end{array}$ \\
\hline $\begin{array}{l}\mathrm{P}_{2} \mathrm{O}_{5} \\
\mathrm{CaO} \\
\mathrm{CO}_{2} \\
\mathrm{Fe}_{2} \mathrm{O}_{3} \\
\mathrm{SO}_{3} \\
\mathrm{~F} \\
\mathrm{MgO} \\
\mathrm{R}_{2} \mathrm{O}_{3} \\
\text { в том числе суммарное со }\end{array}$ & $\begin{array}{r}27,40 \\
39,50 \\
3,05 \\
2,55 \\
2,42 \\
2,58 \\
1,03 \\
3,09\end{array}$ & $\begin{array}{r}27,70 \\
42,68 \\
6,68 \\
3,13 \\
4,50 \\
2,66 \\
2,80 \\
3,67\end{array}$ & $\begin{array}{r}28,80 \\
41,20 \\
3,39 \\
2,85 \\
5,48 \\
2,73 \\
1,30 \\
3,42\end{array}$ & $\begin{array}{r}28,50 \\
44,06 \\
7,51 \\
1,15 \\
0,46 \\
2,68 \\
3,14 \\
1,72\end{array}$ & $\begin{array}{r}39,20 \\
52,00 \\
0,17 \\
0,37 \\
0,15 \\
3,28 \\
\overline{1,95}\end{array}$ & $\begin{array}{r}37,80 \\
52,70 \\
2,60 \\
0,22 \\
0,20 \\
1,06 \\
2,85 \\
0,64\end{array}$ \\
\hline держанне оксидов РЗЭ & 0,32 & 0,30 & 0,20 & 0,18 & 0,90 & 0,45 \\
\hline $\begin{array}{l}\text { Нерастворимый остаток } \\
\text { Отношение, \% }\end{array}$ & 18,30 & 9,3 & 14,5 & 9,3 & 1,17 & 0,74 \\
\hline$\frac{\Sigma \mathrm{Ln}_{2} \mathrm{O}_{3}}{\mathrm{P}_{2} \mathrm{O}_{5}}$ & 1,18 & 1,08 & 0,69 & 0,63 & 2,29 & 1,21 \\
\hline
\end{tabular}

Таблица 2

Содержание редкоземельных элементов в фосфатных концентратах, г/т

\begin{tabular}{|c|c|c|c|c|c|c|}
\hline \multirow{2}{*}{ Элемент } & \multicolumn{5}{|c|}{ Месторождение } & \multirow[b]{2}{*}{ Ковдорское } \\
\hline & Тоолсе & Рягавере & Маарду & Кингисепп & Кольское & \\
\hline $\begin{array}{l}\mathrm{La} \\
\mathrm{Ce} \\
\mathrm{Pr} \\
\mathrm{Nd} \\
\mathrm{Sm} \\
\mathrm{Eu} \\
\mathrm{Gd} \\
\mathrm{Tb} \\
\mathrm{Dy} \\
\mathrm{Ho} \\
\mathrm{Er} \\
\mathrm{Tm} \\
\mathrm{Yb} \\
\mathrm{Lu} \\
\mathrm{Y}\end{array}$ & $\begin{array}{c}135 \\
282 \\
2,8 \\
149 \\
84 \\
6,9 \\
-7,9 \\
-\overline{0} \\
0,2 \\
0,2 \\
1,9 \\
15,1 \\
1,4 \\
1080\end{array}$ & $\begin{array}{c}100 \\
181 \\
3,5 \\
92 \\
52 \\
4,2 \\
0,2 \\
4,7 \\
1,4 \\
0,3 \\
- \\
1,6 \\
11,2 \\
1,0 \\
990\end{array}$ & $\begin{array}{c}85 \\
167 \\
3,0 \\
81 \\
3,8 \\
4,3 \\
0,3 \\
3,6 \\
0,6 \\
- \\
\overline{-} \\
0,9 \\
9,6 \\
0,9 \\
900\end{array}$ & $\begin{array}{c}54 \\
95 \\
\overline{48} \\
24 \\
1,9 \\
0,5 \\
2,7 \\
0,8 \\
- \\
\overline{0} \\
0,4 \\
5,8 \\
0,5 \\
920\end{array}$ & $\begin{array}{c}1253 \\
1210 \\
1,5 \\
351 \\
147 \\
11,8 \\
0,5 \\
4,8 \\
6,7 \\
3,2 \\
0,8 \\
1,8 \\
5,1 \\
1,0 \\
1100\end{array}$ & $\begin{array}{c}185 \\
314 \\
1,0 \\
127 \\
45 \\
4,7 \\
0,8 \\
2,3 \\
3,4 \\
1,8 \\
0,6 \\
0,9 \\
5,5 \\
0,8 \\
1100\end{array}$ \\
\hline
\end{tabular}

определяли методами атомно-абсорбционной спектроскопии (AAC) и нейтронно-активационного анализа (HAA). АAC выполнили на приборе VARIAN-AAS 5 при сжигании смеси $\mathrm{N}_{2} \mathrm{O}$ с ацетиленом; образцы переводили в раствор царской водкой. Для НАА использовали автоматический анализатор системы Canberra 8683 А с пневматической подачей образцов (без предварительной их подготовки) в атомный реактор, работающий на обогащенном уране с потоком нейтронов до $2,4 \cdot 10^{11} \mathrm{~cm}^{-2} \cdot \mathrm{c}^{-1}$. табл. 2.

Полученные данные (средние по обоим методам) приведены в

Анализ данных табл. 2 показывает, что в составе эстонских фосфоритов присутствуют в качестве микропримесей практически все Р3Э в концентрациях от 0,2 до 282 г/т. Количественно преобладают лантаноиды цериевой подгруппы, что характерно для земной коры в целом [ $\left.{ }^{2}\right]$. Иттриевая подгруппа, состоящая из гадолиния, тербия, диспрозия, гольмия, эрбия, тулия, иттербия и лютеция, представлена незна- 


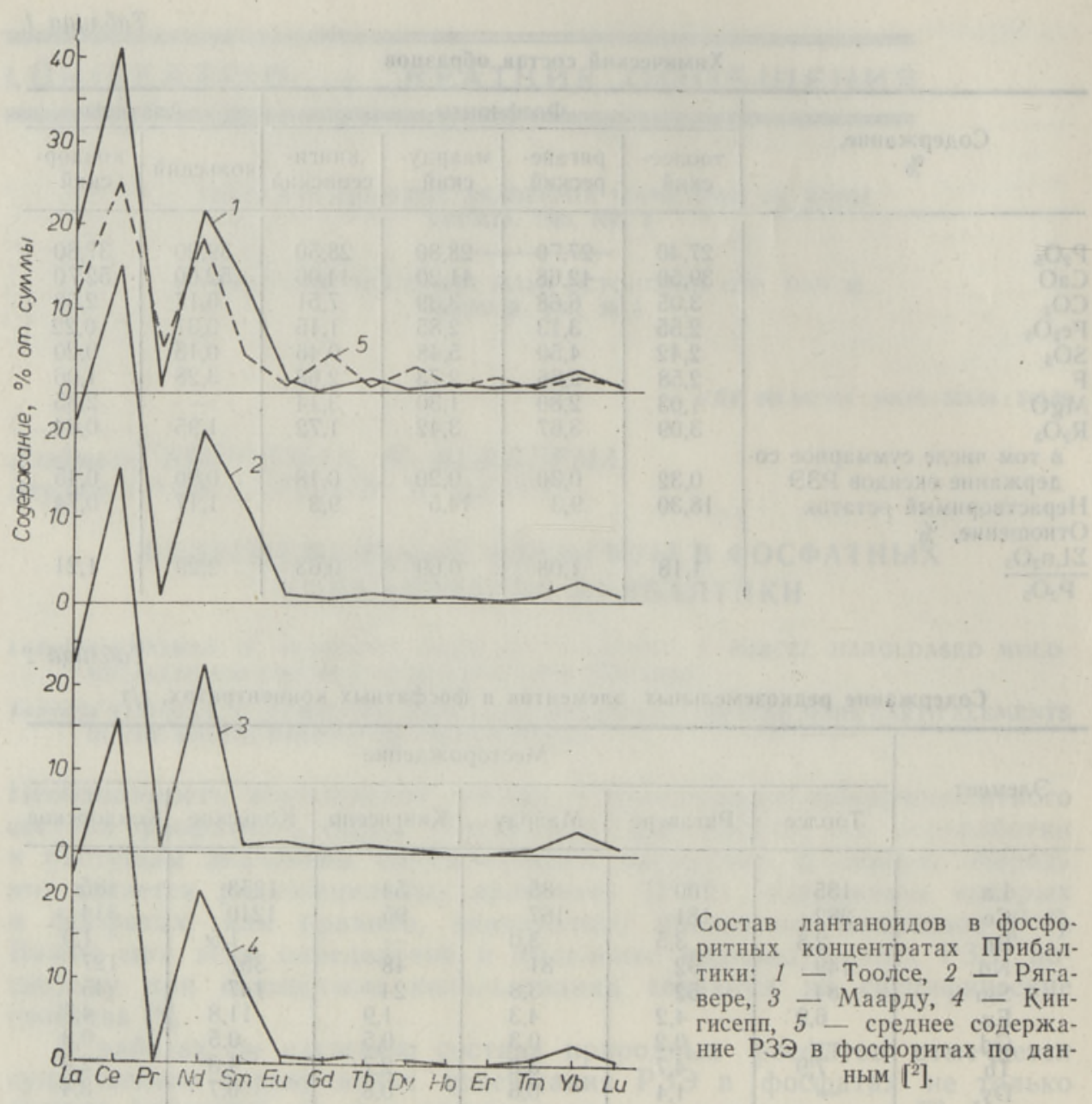

чительно, содержание некоторых из этих элементов, вероятно, ниже предела обнаружения данными методами анализа. Вместе с тем установлена повышенная концентрация иттрия (до 1080 г/т), что подтверждает иттриеносность фосфатных минералов [7], в особенности осадочных фосфоритов [ $\left.{ }^{9}\right]$.

Состав лантаноидов в фосфоритах Прибалтики показан на рисунке, где кривая 5 приведена для сравнения. Распределение лантаноидов в изученных апатитовых концентратах носит аналогичный характер. Эстонские фосфориты, как и ковдорский апатит, обладают явно выраженным цериевым максимумом (около 40\% от суммы РЗЭ), для кольского апатита характерен лантаново-цериевый максимум. Повышенное содержание неодима в эстонских фосфоритах $\left[{ }^{4}\right]$ подтверждают и наши определения: на долю неодима приходится примерно $20 \%$ всех Р3Э. Наблюдается также повышенное по сравнению с апатитовыми концентратами содержание самария и иттербия. Сравнение кривых 1 -4 и 5 показывает, что распределение лантаноидов в изученных образцах мало отличается от среднего распределения РЗЭ в фосфоритах, лишь концентрации некоторых элементов иттриевой подгруппы (гадолиния, диспрозия и гольмия) ниже средних.

Таким образом, при комплексной переработке фосфатного сырья эстонские фосфориты могут служить источником лантана, церия, неодима, иттрия и других ценных РЗЭ. 
1. Холодов В. Н. О редких и радноактивных элементах в фосфоритах. - Тр. Ин-та минералогии, геохимии и кристаллохимии редких элементов, 1963, вып. 17, $67-108$.

2. Семенов Е. И., Холодов В. Н., Баринский Р. Л. Редкие земли в фосфоритах. Геохимия, 1962, № 5, 434-438.

3. Mikulski, T. Apatyty i fosforyty jako miejsce geochemicznej koncentracji pierwiastkow rzadkich, - II Sympozjum Pierwiastki rzadkie i metalurgia chemiczna, Cz. III. Wroclaw, 1973, 73-83.

4. Коган Б. И. Редкие металлы. М., 1979, 124.

5. Лоог А. Редкие земли в оболовых фосфоритах Эстонин. - Изв. АН ЭССР. Хим. Геол., 1968, 17, № 4, 433-435.

6. Вийсимаа Л. П., Вейдерма М. А. Эстонские фосфориты как возможные источники редкоземельных элементов. - В кн.: Тезисы докладов II Всесоюзного совещания по химии и технологии редких и рассеянных элементов. Ереван, 1981, 39.

7. Лештаева $T$. Г. Әкспрессный метод фотометрического определения РЗЭ с арсеназо III в апатитовом концентрате. - В кн.: Методы анализа руд Кольского полуострова. Апатиты, 1970, 160.

8. Холодов В. Н., Минеев Д. А. Редкие элементы в фосфоритах. - В кн.: Вещественный состав фосфоритов. Новосибирск, 1979, 46-65.

9. Altschuler, Z. The Bearing of Geochemistry on the Recovery of Uranium and Rare Earths in Phosphorites. - In: 2nd International Congress of Phosphorus Compounds. Boston, 1980, 605-626.

Таллинский политехнический институт

Поступила в редакцию

Будапештский технический университет 